\title{
Thoracic combined spinal epidural anesthesia for laparoscopic cholecystectomy in a geriatric patient with ischemic heart disease and renal insufficiency
}

\author{
This article was published in the following Dove Press journal: \\ Local and Regional Anesthesia \\ 2 December 2015 \\ Number of times this article has been viewed
}

\author{
Nandita Mehta \\ Sunana Gupta \\ Atul Sharma \\ Mohd Reidwan Dar \\ Department of Anesthesiology and \\ Intensive Care, Acharya Shri Chander \\ College of Medical Sciences and \\ Hospital, Jammu, Jammu and Kashmir, \\ India
}

\begin{abstract}
Older people undergoing any surgery have a higher incidence of morbidity and mortality, resulting from a decline in physiological reserves, associated comorbidities, polypharmacy, cognitive dysfunction, and frailty. Most of the clinical trials comparing regional versus general anesthesia in elderly have failed to establish superiority of any single technique. However, the ideal approach in elderly is to be least invasive, thus minimizing alterations in homeostasis. The goal of anesthetic management in laparoscopic procedures includes management of pneumoperitoneum, achieving an adequate level of sensory blockade without any respiratory compromise, management of shoulder tip pain, provision of adequate postoperative pain relief, and early ambulation. Regional anesthesia fulfills all the aforementioned criteria and aids in quick recovery and thus has been suggested to be a suitable alternative to general anesthesia for laparoscopic surgeries, particularly in patients who are at high risk while under general anesthesia or for patients unwilling to undergo general anesthesia. In conclusion, we report results of successful management with thoracic combined spinal epidural for laparoscopic cholecystectomy of a geriatric patient with ischemic heart disease with chronic obstructive pulmonary disease and renal insufficiency.
\end{abstract}

Keywords: geriatric anesthesia, bupivacaine, segmental anesthesia, laparoscopic surgery

\section{Case report}

An 88-year-old male (weight $45 \mathrm{~kg}$, height $165 \mathrm{~cm}$ ) was admitted in our hospital for elective laparoscopic cholecystectomy. He had a history of frequent right hypochondrial pain with ultrasonography-documented multiple small calculi in the gallbladder. The patient was a known case of chronic obstructive pulmonary disease (COPD) with a moderate obstructive pattern on pulmonary function testing. He also had a history of ischemic heart disease with an old inferior wall myocardial infarction 2 years before, which was managed conservatively, and was presently not on any treatment (having stopped treatment on his own). He had a history of dyspnea on minimal exertion (New York Heart Association [NYHA] class III). The patient had a history of frequent intake of diclofenac sodium for joint pains and stiffness and a history of transurethral resection of prostate done 3 years before under regional anesthesia (no records were available). On examination, blood pressure and heart rate were 130/78 $\mathrm{mmHg}$ and 76 beats/min, respectively. On auscultation, the first and second heart sounds were audible with no added sound. Wheeze was heard on auscultation of the chest on the left side. On airway examination, neck movements (both extension and flexion)
Correspondence: Mohd Reidwan Da Department of Anesthesiology and Intensive Care, Acharya Shri Chander College of Medical Sciences and Hospital, Jammu, Jammu and Kashmir, 180017, India

Email mohdreidwandar@rediffmail.com 
were restricted. His routine investigations were within normal range, except urea $(49 \mathrm{mg} / \mathrm{dL})$ and creatinine $(1.1 \mathrm{mg} / \mathrm{dL})$. Electrocardiogram showed left axis deviation, left ventricular hypertrophy, and atrial bigeminy. Echocardiography revealed left ventricular diastolic dysfunction and basal and inferior wall hypokinesia with $50 \%$ left ventricular ejection fraction. The patient was started on ipratropium bromide and fluticasone nebulization twice daily, and doxofylline $400 \mathrm{mg}$ tablet once daily, orally.

After considering the options, and discussing them with the patient, chest physician, cardiologist, and surgeon, written informed consent was taken to administer thoracic combined spinal epidural (CSE) anesthesia, using a CSE set that contained an 18-gauge Tuohy epidural needle, a 27-gauge Whitacre spinal needle, and an epidural catheter. The patient was shifted to the operation theater, and an intravenous (IV) cannula was secured on the left forearm. Routine monitoring, namely pulse oximetry $\left(\mathrm{SpO}_{2}\right)$, noninvasive blood pressure, and electrocardiogram, was started, and baseline parameters were recorded. Radial arterial cannulation was done for invasive blood pressure monitoring. CSE was performed with the patient in the sitting position; block was performed at the tenth thoracic interspace using a midline approach. The epidural space was identified using the "loss of resistance" to air method. After entering the epidural space, a 27-gauge pencil point Whitacre spinal needle was advanced through the Tuohy needle. After a free and clear flow of cerebrospinal fluid was achieved, $1.5 \mathrm{~mL}$ isobaric bupivacaine $0.5 \%$ and $25 \mu \mathrm{g}$ fentanyl was injected and then the spinal needle was removed. The epidural catheter was then threaded into place and fixed at $4 \mathrm{~cm}$ within the epidural space. Immediately, the patient was made to lie down in the supine position. Oxygen at $2 \mathrm{~L} / \mathrm{min}$ was given using nasal prongs. Within 5 minutes, a segmental sensory (pinprick) block, extending between the T3 and L2 dermatomes, was obtained. Motor block (modified Bromage scale 1-inability to raise extended legs/can bend knee) was achieved after 15 minutes. When surgery was started, there were no signs of respiratory distress. The patient had two episodes of hypotension, one at 10 minutes and another 30 minutes after block; both were managed with a single dose of mephentermine $6 \mathrm{mg}$ each. There were no episodes of bradycardia, arrhythmia, nausea/vomiting, shoulder pain, or pruritus.

Laparoscopic cholecystectomy was commenced after creating pneumoperitoneum with $\mathrm{CO}_{2}$, with a flow rate of $1.8 \mathrm{~L} / \mathrm{min}$ and intra-abdominal pressure of $8 \mathrm{mmHg}$. The gallbladder was removed uneventfully, and the total surgical time was 25 minutes. One liter of crystalloid fluid was given perioperatively.

Postoperatively, the patient was shifted to the surgical intensive care unit for close observation. He remained hemodynamically stable postoperatively and required epidural analgesia ( $8 \mathrm{~mL}$ of 0.125 bupivacaine) three times in the next 24 hours. However, the patient developed acute urinary retention, for which he was catheterized. The Foley catheter was removed on the next day. The epidural catheter was removed on the second postoperative day of surgery. The patient was followed up for 2 days while he remained in the hospital, and during his stay he remained comfortable and hemodynamically stable.

\section{Discussion}

Older people undergoing any operative procedure have a higher incidence of morbidity and mortality, resulting from interaction of various factors like decline in physiological reserves, associated comorbidities, polypharmacy, cognitive dysfunction, and frailty. The goal of achieving good-quality care for elderly patients is difficult, but can be achieved by a team approach involving family physicians, geriatricians, surgeons, anesthetists, intensivists, and, most importantly, the family members. ${ }^{1}$

Aging results in a decrease in physiological reserves, most importantly in cardiac, respiratory, neurologic, and renal function. Alteration in the pharmacokinetics and pharmacodynamics mandates adjustment of dosage or avoidance of particular drugs. The use of multiple medications for various coexisting morbidities may alter the homeostatic mechanisms and increase the risk of dangerous drug interactions. The response of such patients to surgical stress may be unpredictable.

The ideal approach in elderly is to be least invasive, thus minimizing alterations in homeostasis. Most of the clinical trials comparing regional versus general anesthesia in elderly have failed to establish superiority of any single technique over another. ${ }^{2,3}$ However, there are some advantages with regional anesthesia, due to which most anesthesiologists prefer regional anesthesia. Regional anesthesia does not require instrumentation of the airway and allows patients to maintain their own airway and level of pulmonary function, and these patients have lower risk of hypoxemia. ${ }^{4}$ Recent data confirm the earlier belief that regional anesthesia decreases the hypercoagulable tendency in the postoperative period and helps maintain normal coagulation and platelet function, probably due to modulation of the neuroendocrine response to tissue injury. There is evidence that homeostasis 
of the neuroendocrine system and the immune responses are better preserved after regional anesthesia than after general anesthesia. $^{5}$

Regional anesthesia is an acceptable technique in patients with ischemic heart disease. However, the decrease in blood pressure associated with epidural or spinal anesthesia must be controlled. Segmental blockade may be more suitable, as more dermatomes blocked means more vasodilatation and more hemodynamic instability. However, if hypotension occurs, prompt treatment is necessary. Potential benefits of a regional anesthesia in the cardiac patient include excellent pain control, decreased neuroendocrine response, a decreased incidence of deep vein thrombosis in some patients, and the opportunity to continue the block into the postoperative period.

We chose thoracic segmental anesthesia because it offers us better hemodynamic stability, better analgesia, faster ambulation, and better patient satisfaction than lumbar spinal or general anesthesia. ${ }^{6}$ Another advantage is lesser doses of drugs being used in thoracic segmental block compared to other techniques. Moreover, the isobaric drug, does not spread extensively thus causing segmental blockade and position changes initially Trendelenburg and later reverse Trendelenburg do not affect the block height. The safety of giving thoracic spinal anesthesia has been established by clinical and radiological studies. Imbelloni et $\mathrm{al}^{7}$ studied the anatomy of the thoracic spinal canal with magnetic resonance imaging (MRI) in 50 patients. The space between the dura mater and spinal cord in the thoracic region measured with MRI was $5.19 \mathrm{~mm}$ at T2, $7.75 \mathrm{~mm}$ at T5, and $5.88 \mathrm{~mm}$ at T10. An angle of entry almost $50^{\circ}$ further elongates the distance from the tip of the needle to the posterior surface of the cord. Furthermore, use of a CSE system which limits the length of needle which can project beyond the tip of the epidural needle also minimizes the risk of contact with neural tissue. The sitting position for neuraxial block further increases the margin of safety, as shown by Lee et al, ${ }^{8}$ who investigated, with MRI, the human anatomic positions of the spinal canal (eg, spinal cord, thecal tissue) in various postures and found that, in a head-down sitting posture, the posterior separation of the dura mater and spinal cord is increased.

The stress or sympathetic response to surgery causes increased release of catecholamines; in one study, a threefold increase in norepinephrine level was detected up to 24 hours after surgery. ${ }^{9}$ These stress hormones pose a significant risk to elderly patients in terms of negative nitrogen balance, stress hyperglycemia, and altered immune function. Moreover, patients of ischemic heart disease respond paradoxically to stress hormones by causing vasoconstriction in arteriosclerotic coronary arteries. Thoracic epidural anesthesia has been found in many studies to vasodilate stenotic coronaries, thus reducing the number and duration of cardiac ischemic episodes. ${ }^{10,11}$ The benefit of a thoracic epidural in improving myocardial structure and functioning after coronary artery bypass grafting has been proved by many studies. ${ }^{9}$

Better pain control than opioids and early ambulation decrease the risk of postoperative pulmonary complications, resulting in a shortened stay in hospitals. Thoracic epidural analgesia and starting enteral feeding early have been associated with earlier return of gastrointestinal function. ${ }^{12}$

The goals of anesthetic management in COPD are: avoidance of respiratory depressant drugs and drugs causing impairment of mucociliary clearance; avoidance of mechanical ventilation; providing good analgesia, especially in upper abdominal surgeries, to prevent worsening in respiratory mechanics; and early ambulation. Thoracic CSE well fulfills these requirements, and there are many case reports of laparoscopic cholecystectomy in patients with severe COPD done under regional anesthesia. ${ }^{13-15}$

There are no comparative studies demonstrating superior renal protection or improved renal outcome with general versus regional anesthesia. The basic principles to be followed are avoidance of nephrotoxic drugs and drugs with significant renal clearance and avoidance of hypotension. Thoracic CSE has the advantage of achieving a satisfactory level of blockade with low drug volume, and the drugs used are not nephrotoxic. Hemodynamic instability, if caused, should be immediately treated to avoid prolonged decrease in renal blood flow.

\section{Conclusion}

Geriatric patients with limited physiological reserve and associated comorbidities present a challenge to anesthesiologists. Such patients should be thoroughly assessed preoperatively and any condition which may lead to postoperative worsening in homeostasis should be treated optimally. Thoracic CSE with isobaric bupivacaine provides us segmental anesthesia with minimal alteration in baseline physiological state and significant postoperative benefits.

\section{Disclosure}

The authors report no conflicts of interest in this work.

\section{References}

1. Griffiths R, Beech F, Brown A, et al; Association of Anesthetists of Great Britain and Ireland. Peri-operative care of the elderly 2014: Association of Anaesthetists of Great Britain and Ireland. Anaesthesia. 2014;69 Suppl 1:81-98. 
2. Roy RC. Choosing general versus regional anesthesia for the elderly. Anesthesiol Clin North America. 2000;18:91-104.

3. Le-Wendling L, Bihorac A, Baslanti TO et al. Regional anesthesia as compared with general anesthesia for surgery in geriatric patients with hip fracture: does it decrease morbidity, mortality, and health care costs? Results of a single-centred study. Pain Med. 2012;13:948-956.

4. Moller JT, Wittrup M, Johansen SH. Hypoxemia in the postanesthesia care unit: an observer study. Anesthesiology. 1990;73:890-895.

5. Bernstein S, Malhotra V. Regional anesthesia for genitourinary surgery. In: Malhotra V, editor. Anesthesia for Renal Genito-Urologic Surgery. New York: McGraw-Hill; 1996:265.

6. Yousef GT, Lasheen AE. General anesthesia versus segmental thoracic or conventional lumbar spinal anesthesia for patients undergoing laparoscopic cholecystectomy. Anesth Essays Res. 2012;6:167-173.

7. Imbelloni LE, Quirici MB, Ferraz Filho JR, Cordeiro JA, Ganem EM. The anatomy of the thoracic spinal canal investigated with magnetic resonance imaging. Anesth Analg. 2010;110(5):1494-1495.

8. Lee RA, van Zundert AA, Botha CP, et al. The anatomy of the thoracic spinal canal in different postures: a magnetic resonance imaging investigation. Reg Anesth Pain Med. 2010;35(4):364-369.

9. Waurick R, Van Aken H. Update in thoracic epidural anaesthesia. Best Practice \& Research Clinical Anaesthesiology. 2005;19(2):201-213.
10. Liu S, Wu C. Effect of postoperative analgesia on major postoperative complications: A systemic update of the evidence. Anesthesia \& Analgesia. 2007;104(3):689-702.

11. Peyton P, Myles P, Silbert B. Perioperative epidural analgesia and outcome after major abdominal surgery in high-risk patients. Anesthesia \& Analgesia. 2003;96(2):548-554.

12. Nygård E, Kofoed KF, Freiberg J, et al. Effects of high thoracic epidural analgesia on myocardial blood flow in patients with ischemic heart disease. Circulation. 2005;111(17):2165-2170.

13. van Zundert AA, Stultiens G, Jakimowicz JJ, van den Borne BE, van der Ham WG, Wildsmith JA. Segmental spinal anaesthesia for cholecystectomy in a patient with severe lung disease. $\mathrm{Br} J$ Anaesth. 2006;96:464-466.

14. Gramatica L, Brasesco OE, Mercado Luna A, et al. Laparoscopic cholecystectomy performed under regional anesthesia in patients with obstructive pulmonary disease. Surg Endosc. 2002;16:472-475.

15. Pursnani KG, Bazza Y, Calleja M, Mughal MM. Laparoscopic cholecystectomy under epidural anesthesia in patients with chronic respiratory disease. Surg Endosc. 1998;12:1082-1084.

\section{Publish your work in this journal}

Local and Regional Anesthesia is an international, peer-reviewed, open access journal publishing on the development, pharmacology, delivery and targeting and clinical use of local and regional anesthetics and analgesics. The journal welcomes submitted papers covering original research, basic science, clinical studies, reviews \& evaluations,

\section{Dovepress}

guidelines, expert opinion and commentary, case reports and extended reports. The manuscript management system is completely online and includes a very quick and fair peer-review system, which is all easy to use. Visit http://www.dovepress.com/testimonials.php to read real quotes from published authors. 